\title{
Production of UN kernels with Gd additive as burnable absorber
}

Fuel Cycle Research \& Development Advanced Fuels Campaign

JW McMurray

RD Hunt

CM Silva

GW Helmreich

RL Seibert

Prepared for

U. S. Department of Energy Office of Nuclear Energy

March 2018 M3NT-18OR02020107 


\section{DISCLAIMER}

This information was prepared as an account of work sponsored by an agency of the U.S. Government. Neither the U.S. Government nor any agency thereof, nor any of their employees, makes any warranty,

expressed or implied, or assumes any legal liability or responsibility for the accuracy, completeness, or usefulness, of any information, apparatus, product, or process disclosed, or represents that its use would not infringe privately owned rights. References herein to any specific commercial product, process, or service by trade name, trade mark, manufacturer, or otherwise, does not necessarily constitute or imply its endorsement, recommendation, or favoring by the U.S. Government or any agency thereof. The views and opinions of authors expressed herein do not necessarily state or reflect those of the U.S. Government or any agency thereof. 


\title{
Production of UN kernels with Gd additive as burnable absorber
}

\author{
JW McMurray \\ RD Hunt \\ CM Silva \\ GW Helmreich \\ RL Seibert
}

March 2018

Prepared by

OAK RIDGE NATIONAL LABORATORY

Oak Ridge, TN 37831-6283

managed by

UT-BATTELLE, LLC

for the

US DEPARTMENT OF ENERGY

under contract DE-AC05-00OR22725 

INTENTIONALLY BLANK 


\begin{abstract}
Uranium nitride has a high $\mathrm{U}$ density that is an important property for the accident tolerant fully ceramic microencapsulated fuel design. Gadolinium is burnable poison important for flattening the reactivity of the fuel. The impact of the chemical form of $\mathrm{Gd}$ additions to the sol-gel feedstock was investigated in this work. Densities were higher when Gd was incorporated as a nitrate hexahydrate and lower when added as a sesquioxide.
\end{abstract}


INTENTIONALLY BLANK 


\section{CONTENTS}

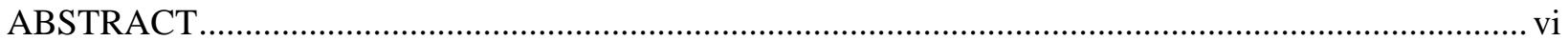

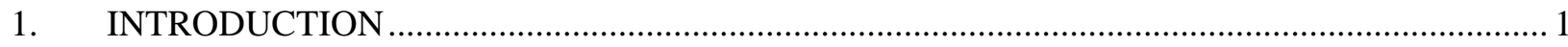

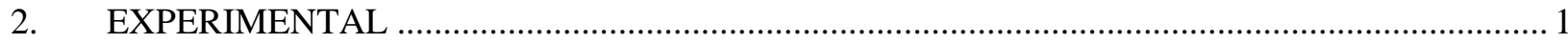

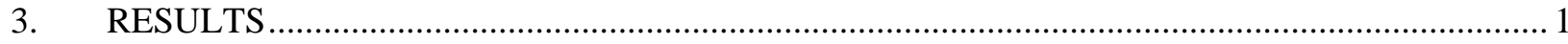

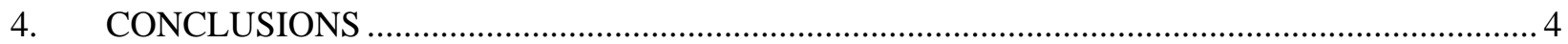

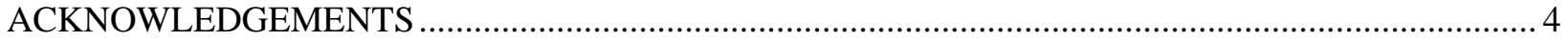

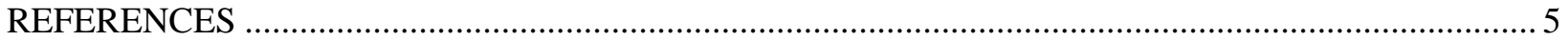

\section{FIGURES}

Figure 1 Lattice parameter vs $\mathrm{x}$ in $\mathrm{UC}_{\mathrm{x}} \mathrm{UN}_{1-\mathrm{x}}$ compared to LECO measured $\mathrm{C}$ content............................ 2

Figure 2 SE-SEM micrograph and EDS elemental maps of a selected region of UNF-Gd3 sample.

Bottom-left shows a composite U-Gd-O elemental map. A few O-free and Gd-rich grain areas are highlighted by arrows in $\mathrm{Gd}$ and $\mathrm{O}$ maps.

Figure 3 Typical microstructures of FCM-UN1 (a-b), UNF-Gd2 (c-d), and UNF-Gd3 (e-f). Highresolution micrographs in each case was obtained focusing on the center of the samples.

\section{TABLES}

Table 1 Details of the feedstock along with the phases present, the overall density, and composition of corresponding $\mathrm{UC}_{1-\mathrm{x}} \mathrm{N}_{\mathrm{x}}$ kernels as determined from XRD. Note, SEM shows $\mathrm{Gd}$ as a second phase precipitate in UNF-Gd2 and UNF-Gd3. 


\section{Production of UN kernels with Gd additive as burnable absorber}

\section{INTRODUCTION}

Uranium nitride (UN) has a high U density, an important property for the accident tolerant fuel (ATF) design. For example, it can be used as the kernel of TRISO (tristructural-isotropic) particles in an FCM (fully ceramic microencapsulated) compact. In FCM, UN microspheres are coated with TRISO layers that are established primary barriers to radionuclide release [1]. These UN loaded TRISO particles are then embedded in a dense $\mathrm{SiC}$ matrix that serves as additional secondary containment and has been shown to substantially retard steam ingress resulting from a breach of cladding event [2]. The FCM design therefore significantly enhances safety margins during accident events.

George et al. [3] identified a technological challenge associated with use of UN as the fuel kernel for FCM, that is, the reactivity must be decreased at the beginning of life with a burnable poison. Therefore, the focus of this work is to explore the impact of Gd additions to the sol-gel feedstock to produce UN with Gd microspheres. Particular attention is given to the effect on the final density after carbothermic reduction and nitriding (CTRN) compared to benchmark UN.

\section{EXPERIMENTAL}

The sol-gel feedstock technique and equipment has been detailed in previous reports [4-10] and remains unchanged for this work with two exceptions. First, each feed solution contained either Mogul L carbon black or Raven 3500 both from the Cabot Corporation. Second, either Gd in the chemical form of $\mathrm{Gd}_{2} \mathrm{O}_{3}$ nanopowder or $\mathrm{Gd}\left(\mathrm{NO}_{3}\right)_{3} 6 \mathrm{H}_{2} \mathrm{O}$ (gadolinium nitrate hexahydrate) 99.9 wt \% purity from SigmaAldrich was added to the acid deficient uranyl nitrate (ADUN) feed solution.

The recommended process variables for carbothermic reduction and nitriding of the sol-gel feedstock was reported by Lindemer et al. [7]. To be consistent, temperature ramps and flow rates from [7, 8] were reproduced. As in [9], all experiments were conducted using a STA 449 F3 Jupiter from NETZSCH-

Gerätebau $\mathrm{GmbH}$. The process gasses were certified to be within their impurity limits reported by Airgas described in Table 1 of [9].

\section{RESULTS}

The properties of the feedstock and the converted UN kernels from seven separate samples are summarized in Table 1. The UC composition was determined using the polynomial fit and the reported lattice parameters for the UN and UC endmembers determined in $[7,8]$. The results of this method were compared to LECO measurements and found to be in excellent agreement as illustrated by Figure 1. 
Figure 1 Lattice parameter vs $\mathrm{x}$ in $\mathrm{UC}_{\mathrm{x}} \mathrm{UN}_{1-\mathrm{x}}$ compared to LECO measured $\mathrm{C}$ content using the polynomial fit from $[7,8]$. The dotted line is calculated using Vegard's law.

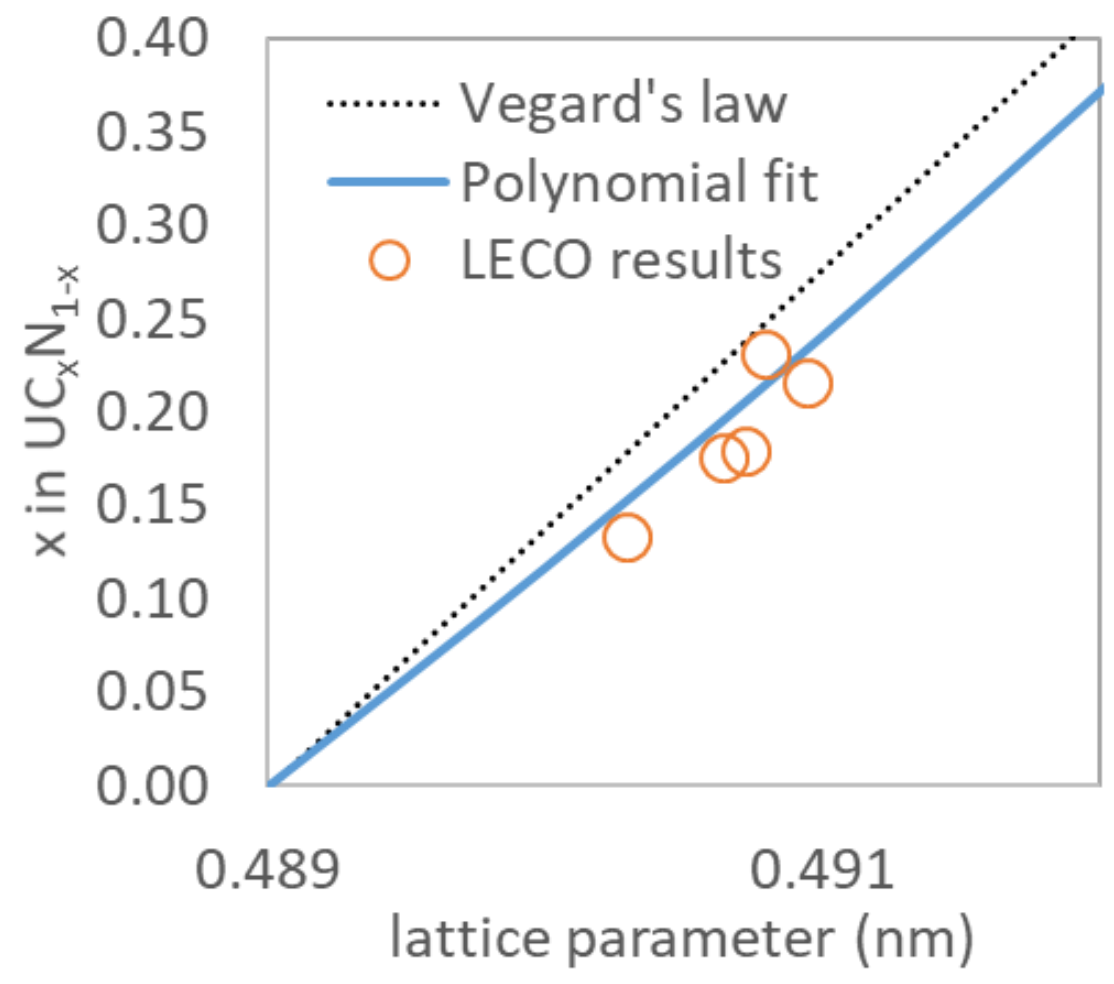

Table 1 Details of the feedstock along with the phases present, the overall density, and composition of corresponding $\mathrm{UC}_{1-\mathrm{x}} \mathrm{N}_{\mathrm{x}}$ kernels as determined from XRD.

\begin{tabular}{|c|c|c|c|c|c|c|}
\hline \multirow{2}{*}{ Sample } & \multirow{2}{*}{$\begin{array}{l}\text { Sol-gel molar } \\
\text { ratios }\end{array}$} & \multirow{2}{*}{ Carbon } & \multirow{2}{*}{ Additive } & \multicolumn{2}{|c|}{ Density g/cc } & \multirow{2}{*}{$\begin{array}{c}\text { XRD } \\
\text { analysis }\end{array}$} \\
\hline & & & & $\mathrm{N}_{2}$ Pycnometry & Shadow imaging & \\
\hline UNF-Gd & $\begin{array}{l}\mathrm{C} / \mathrm{U}-2.590 \\
\mathrm{Gd} / \mathrm{U}-0.025\end{array}$ & Mogul L & $\begin{array}{c}\mathrm{Gd}_{2} \mathrm{O}_{3} \\
\text { nanopowder }\end{array}$ & NA & $9.64 \pm 0.11^{\dagger}$ & $\mathrm{UC}_{0.11} \mathrm{~N}_{0.89}$ \\
\hline UNF-Gd2 & $\begin{array}{l}\mathrm{C} / \mathrm{U}-2.525 \\
\mathrm{Gd} / \mathrm{U}-0.025\end{array}$ & Mogul L & $\mathrm{Gd}\left(\mathrm{NO}_{3}\right)_{3} 6 \mathrm{H}_{2} \mathrm{O}$ & $13.14 \pm 0.01$ & $13.41 \pm 0.08$ & $\mathrm{UC}_{0.21} \mathrm{~N}_{0.79}$ \\
\hline UNF-70/3500 & $\mathrm{C} / \mathrm{U}-2.500$ & Raven 3500 & none & $12.98 \pm 0.01$ & $13.19 \pm 0.14$ & $\mathrm{UC}_{0.14} \mathrm{~N}_{0.86}$ \\
\hline FCM-4A-UN-A & $\mathrm{C} / \mathrm{U}-2.650$ & Mogul L & none & $13.02 \pm 0.04$ & $12.84 \pm 0.07$ & $\mathrm{UC}_{0.20} \mathrm{~N}_{0.80}$ \\
\hline FCM-4E-UN1 & $\mathrm{C} / \mathrm{U}-2.650$ & Mogul L & none & $12.99 \pm 0.01$ & $12.97 \pm 0.05$ & $\mathrm{UC}_{0.19} \mathrm{~N}_{0.81}$ \\
\hline FCM-4D-UN1 & $\mathrm{C} / \mathrm{U}-2.650$ & Mogul L & none & $13.06 \pm 0.04$ & $12.89 \pm 0.05$ & $\mathrm{UC}_{0.23} \mathrm{~N}_{0.77}$ \\
\hline UNF-Gd3 & $\begin{array}{l}\mathrm{C} / \mathrm{U}-2.500 \\
\mathrm{Gd} / \mathrm{U}-0.125\end{array}$ & Raven 3500 & $\mathrm{Gd}\left(\mathrm{NO}_{3}\right)_{3} 6 \mathrm{H}_{2} \mathrm{O}$ & $13.18 \pm 0.01$ & $13.66 \pm 0.22$ & $\begin{array}{c}\mathrm{Gd}_{2} \mathrm{O}_{3}, \\
\mathrm{UC}_{0.11} \mathrm{~N}_{0.89}\end{array}$ \\
\hline
\end{tabular}

${ }^{\dagger}$ Average density of 20-30 microspheres computed from weights and diameters measured with an optical microscope.

Kernel densities were calculated with both with an AccuPyc II Gas Displacement Pycnometer from Micromeritics or by combining measurements of kernel radii with measured mean kernel masses, heretofore referred to as "shadow imaging," described previously in detail in [7-9, 11]. 
Figure 2 SE-SEM micrograph and EDS elemental maps of a selected region of UNF-Gd3 sample. Bottom-left shows a composite U-Gd-O elemental map. A few O-free and Gd-rich grain areas are highlighted by arrows in Gd and $\mathrm{O}$ maps.

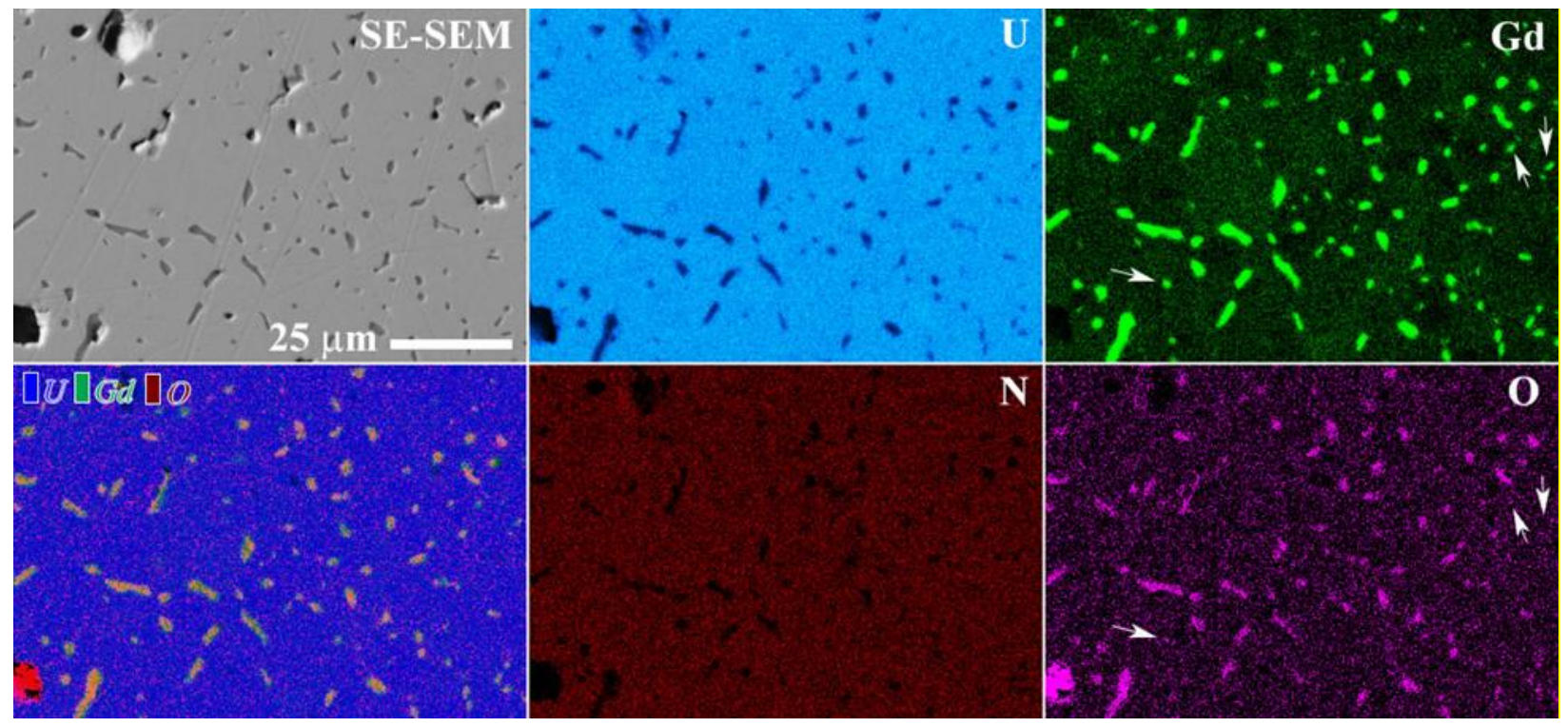

Figure 3 Typical microstructures of FCM-UN1 (a-b), UNF-Gd2 (c-d), and UNF-Gd3 (e-f). High-resolution micrographs in each case was obtained focusing on the center of the samples.

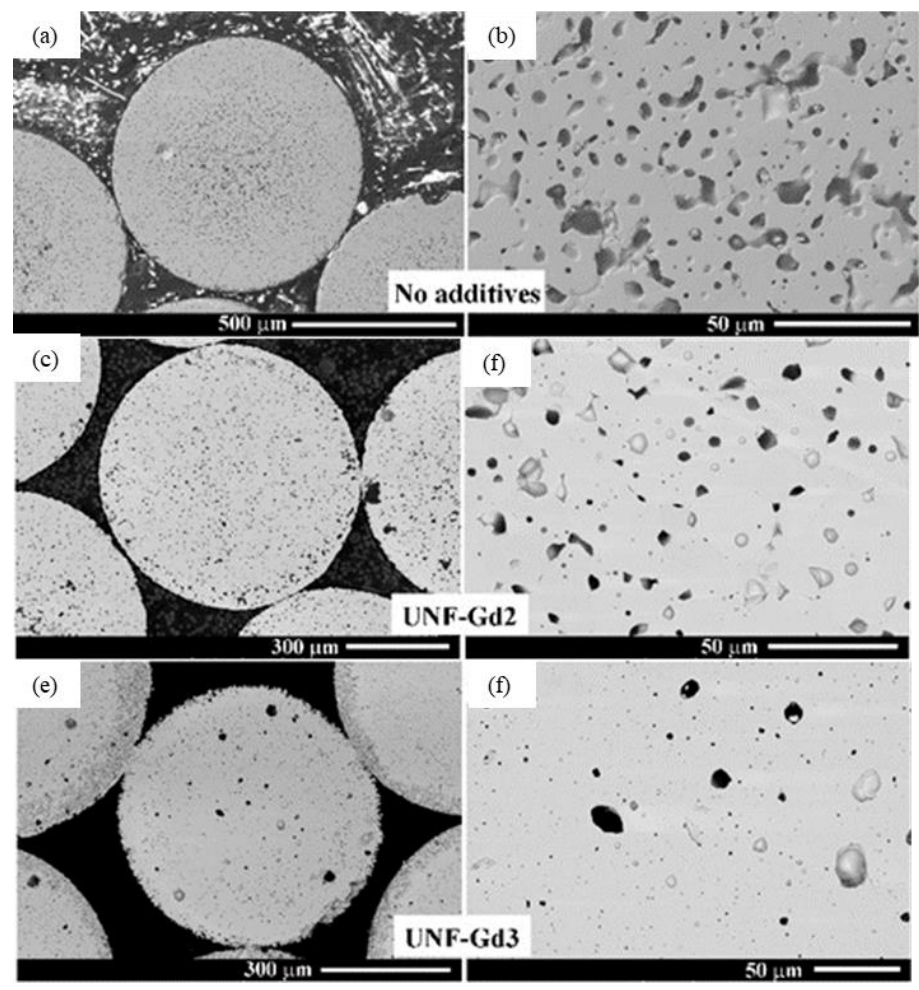




\section{CONCLUSIONS}

The samples with $\mathrm{Gd}$ added using gadolinium nitrate hexahydrate, $\mathrm{Gd}\left(\mathrm{NO}_{3}\right)_{3} 6 \mathrm{H}_{2} \mathrm{O}$ showed clear increases in density over those without it prepared with the same carbon, dispersant and processing parameters. Gadolinium mononitride is isostructural with UN; it was anticipated for the added Gd to be incorporated into the $\mathrm{UN}$ matrix to form $(\mathrm{U}, \mathrm{Gd}) \mathrm{N}$. One aim of this work was to determine if solid solution sintering densification mechanisms [12-15] would be active. Since the XRD results for the sample with $0.125 \mathrm{Gd}$ by metal fraction showed $\sim 12.5 \mathrm{wt} \% \mathrm{Gd}_{2} \mathrm{O}_{3}$, it is not known whether the densification mechanism results from the solid solution, precipitation, or some combination thereof.

The density decreased significantly over the baseline for Gd added as an oxide in the form of $\mathrm{Gd}_{2} \mathrm{O}_{3}$. It is proposed that $\mathrm{Gd}$ is better mixed when added as $\mathrm{Gd}\left(\mathrm{NO}_{3}\right)_{3} 6 \mathrm{H}_{2} \mathrm{O}$ which dissolves in the ADUN whereas $\mathrm{Gd}_{2} \mathrm{O}_{3}$ nanoparticles form a suspension. Further, the dispersant effect could be altered by $\mathrm{Gd}_{2} \mathrm{O}_{3}$ resulting in $\mathrm{C}$ agglomerations that are thought to be detrimental to achieving high density kernels [16].

Other rare earths and Th are stable as an nitrate and should be amenable to dissolution by ADUN. Therefore, it is recommended that further studies be conducted into how the oxidation state and ionic radii of additives with mononitrides sharing a $\mathrm{NaCl}$ structure with $\mathrm{UN}$ effect the sintering behavior of $\mathrm{UN}$ in general and, in particular, as microspheres from sol-gel feedstock. For example Eu, like Gd, can be used as a burnable poison and exists as a mixed $2+$ and $3+$ cation. Thorium is a fertile neutron absorber and the 4+ oxidation state predominates. On the other hand, Pr and Ce can exhibit a mixed 3+ and 4+ valence. Important questions to answer are: (1) which of these have the greatest impact on densification? and (2) at what metal fraction? Further, any of the lanthanides, $\mathrm{Pu}$, and the minor actinides should dissolve as nitrates into the ADUN and each should be isomorphic as a nitride with UN.

While the $\mathrm{Gd}$ added as $\mathrm{Gd}\left(\mathrm{NO}_{3}\right)_{3} 6 \mathrm{H}_{2} \mathrm{O}$ has been shown to improve the overall density of $\mathrm{UN}$, it also has the effect of displacing U. According to [3], $12.8 \mathrm{~g} / \mathrm{cm}^{3}$ is required for the FCM design. Using the highest density numbers from this study (those determined with shadow imaging), UNF-Gd2 and UNF$\mathrm{Gd} 3$ result in $12.4 \mathrm{~g} / \mathrm{cm}^{3}$ and $11.8 \mathrm{~g} / \mathrm{cm}^{3}$ respectively. Other routes must be taken to achieve higher $\mathrm{U}$ densities, for example hot isostatic pressing which has been shown to produce up UN microspheres with up to13.1 $\mathrm{g} / \mathrm{cm}^{3}[10]$.

\section{ACKNOWLEDGEMENTS}

The authors are grateful to Dr. Tyler Gerczak and Dr. Stephen Raiman at ORNL for valuable critiques and technical insight. The work presented in this paper was supported by the Advanced Fuels Campaign of the Fuel Cycle R\&D program in the Office of Nuclear Energy, US Department of Energy. 


\section{REFERENCES}

1. Baldwin, C.A., et al., First elevated-temperature performance testing of coated particle fuel compacts from the AGR-1 irradiation experiment. Nuclear Engineering and Design, 2014. 271: p. 131-141.

2. Terrani, K.A., L.L. Snead, and J.C. Gehin, Microencapsulated fuel technology for commercial light water and advanced reactor application. Journal of Nuclear Materials, 2012. 427(1): p. 209224.

3. George, N.M., et al., Neutronics studies of uranium-bearing fully ceramic microencapsulated fuel for pressurized water reactors. Nuclear Technology, 2014. 188(3): p. 238-251.

4. Hunt, R., et al., Preparation of UC 0.07-0.10 N 0.90-0.93 spheres for TRISO coated fuel particles. Journal of Nuclear Materials, 2014. 448(1): p. 399-403.

5. Hunt, R., et al., Preparation of uranium fuel kernels with silicon carbide nanoparticles using the internal gelation process. Journal of Nuclear Materials, 2012. 427(1): p. 245-248.

6. Hunt, R.D., et al., Preparation of spherical, dense uranium fuel kernels with carbon. Radiochimica Acta, 2007. 95(4): p. 225-232.

7. Lindemer, T., et al., Quantification of process variables for carbothermic synthesis of UC 1-x $N x$ fuel microspheres. Journal of Nuclear Materials, 2017. 483: p. 176-191.

8. $\quad$ Lindemer, T.B., et al., Carbothermic Synthesis of 820- $\mu \mathrm{m}$ UN Kernels: Investigation of Process Variables. 2015, Oak Ridge National Laboratory (ORNL), Oak Ridge, TN (United States).

9. McMurray, J.W., et al., Examination of viability of UN kernel production with additives such as SiC and B. 2017, Oak Ridge National Laboratory.

10. McMurray, J.W., J. Kiggans, and K. Terrani, Examination of HIP for production of high density UN kernels. 2017, Oak Ridge National Laboratory.

11. McMurray, J.W., et al., Production of Low Enriched Uranium Nitride Kernels for TRISO Particle Irradiation Testing. 2016, Oak Ridge National Laboratory (ORNL), Oak Ridge, TN (United States).

12. Brook, R., Additives and the sintering of ceramics. Sci. Sintering, 1988. 20(2): p. 115-118.

13. Carter, C.B. and M.G. Norton, Ceramic materials: science and engineering. 2007: Springer Science \& Business Media.

14. De Jonghe, L.C. and M.N. Rahaman, 4.1 Sintering of Ceramics. Handbook of Advanced Ceramics: Materials, Applications, Processing and Properties, 2003. 2: p. 187.

15. Harmer, M., Use of solid-solution additives in ceramic processing. Advances in ceramics, 1984. 10: p. 679.

16. Ebner, M., Chemistry Improvement for the Production of LEU UCO Fuel Using Manufacturing Scale Equipment-FY 2004 Final Report. Idaho: Idaho National Laboratory, 2004. 